\title{
Prior Solutionising Deformation Consequence on the Aging Characteristics of Steel Powder Reinforced Al 7075 Composites
}

\author{
Rajesh, Sathyashankara Sharma, Gowrishankar M C, Manjunath Shettar, Pavan Hiremath, \\ Anand Hegde
}

\begin{abstract}
Globally, in the application of structural materials, aluminum composites are emerging as pioneer materials due to balanced properties like ductility, strength, hardness and weight to volume ratio. It is obvious that addition of harder steel powder reinforcements to the softer aluminum alloy matrix will yield in larger benefits as energy efficient method, durability and recyclability for the composite. Infact, improvement in hardness levels at low temperatures in softer matrix aluminium alloys is the order of the day for wear related applications. Aluminum alloy composites especially Al 7075 matrix containing solid state soluble elements like copper, zinc and silicon with or without wetting agents like magnesium are heat treatable and got medium strength. The alloy matrix dispersed with solid reinforcements like carbides, oxides, flyash and steel powder contribute for the property improvement by tailoring the suitable heat treatment with flexibility in process parameters. Cold deformation assisted heat treatments, prior to or post solutionising challenge conventional heat treatments like age hardening or precipitation hardening. When the cold deformation is provided before solution treatment increases hardness by strain hardening with increased nucleation sites for phase transformation. When partial solutionising is given to the cold deformed composite retains the partial strain hardening effect on the specimen compared to complete solutionising. The retention of partial strain hardening followed by further aging develops complex interaction effect of strain hardening coupled with controlled precipitation of intermetallics on the composite for drastic uplift in hardness property.

During conventional age hardening hardness and strength of the samples increase. Reduction in peak hardness value with increasing aging temperature is the renowned behaviour of age hardenable composites. The obtained peak hardness value is further increasing when cold deformation is supported with prior intentional deformation. Considering these features, it is proposed to perform prior solutionising deformation followed by subsequent aging on the stir cast Al 7075 -steel powder reinforced composite and analyse the microstructure and hardness distribution pattern by varying the steel powder quantity $(0,3$ and $6 w t \%)$, deformation density (10 and 20\%) and aging temperatures (100 and 180oC).
\end{abstract}

Revised Version Manuscript Received on 10 September, 2019.

Rajesh, Department of Mechanical and Manufacturing Engineering, Manipal Institute of Technology, Manipal Academy of Higher Education, Manipal-576104, Karnataka, India.

Sathya Shankara Sharma, Department of Mechanical and Manufacturing Engineering, Manipal Institute of Technology, Manipal Academy of Higher Education, Manipal-576104, Karnataka, India.

Gowrishankar M C, Department of Mechanical and Manufacturing Engineering, Manipal Institute of Technology, Manipal Academy of Higher Education, Manipal-576104, Karnataka, India.

Manjunath Shettar, Department of Mechanical and Manufacturing Engineering, Manipal Institute of Technology, Manipal Academy of Higher Education, Manipal-576104, Karnataka, India.

Pavan Hiremath, Department of Mechanical and Manufacturing Engineering, Manipal Institute of Technology, Manipal Academy of Higher Education, Manipal-576104, Karnataka, India.

Anand Hegde, Department of Mechanical Engineering, Madhva Institute of Technology and Engineering, Udupi, India
There was better distribution of reinforcements in the matrix, higher peak hardness with the increase in deformation density and reinforcement quantity in the matrix. Higher peak hardness is observed at lower aging temperature with reduction in the peak age duration in the composites at all other variable conditions like, reinforcement quantity, degree of deformation.

Index Terms: Al 7075, aging, solutionising, intermetallics, strain hardening.

\section{INTRODUCTION}

It is important to know the properties of material which will use and work under various environmental and mechanical conditions. For the proper selection of materials, it is essential to have a thorough understanding of nature and behaviour of materials under the load and environmental condition to which they are subjected. Heat treatment is one of the ways to alter the structure of the material there by to get the desired properties of the material. Aluminium alloys show good strength to weight ratio, low density, good electrical and thermal conductivity and are often used for heat treatments to improve their qualities. Generally, homogenizing, solutionising, artificial aging and thermo mechanical treatments were given to alter the properties.

Age hardening covers two steps viz., solution annealing (solutionising) and aging. Solutionising makes the high temperature structure possible at lower temperatures as super saturated solid solution on quenching and aging is the timing phenomenon to allow the precipitation of various harder phases by a number of metastable coherent or incoherent intermediate zones [1]. The reasonable better strength of the peak-aged alloy is due to the solid phase strengthening consequence of the complex intermediate phases which are semi or fully coherent with the parent matrix. The stable coarser phases form beyond the peak-age condition [2-4]. Age hardening involves heating the alloy to the solvus temperature for ample time so that alloying elements such as $\mathrm{Be}, \mathrm{Cu}, \mathrm{Mg}$ and $\mathrm{Zn}$ etc. go into solution in stable sold state and form solid solution type alloy. After solution annealing the alloy, is quenched in liquid media at moderate severity so that nonequilibrium room temperature phase is formed in ambient temperature. The variables participating in the heating and cooling process to play in the properties are isothermal holding temperature and time followed by rate of 
cooling [5-7]. Instantaneously quenching makes alloys relatively soft and can be mechanically formed till it ages at reasonably good temperature. Proper solid solution treatment temperature harvests good toughness whereas increased temperature yields unwanted grain coarsening phenomenon [8-9]. The increase in the number of the fine precipitates evolved from parent finer grains would increase the nucleation locations for void instigation to reduce the strength and toughness [9]. Plastic deformation at cold or warm temperature results in the production of various structural defects such as vacancies, dislocation jogs, twist and twin boundaries and stacking faults. These defects have a serious impact on the phase transformation in metal and alloy by providing nucleation sites and abetting diffusion process [10]. This will give rise to increased hardness and strength due to intentional work hardening mechanism. Heating such deformed material with increased lattice defects recrystallizes into finer high temperature phase, remains as finer on quenching at room temperature so that nucleation sites for aging increases [11].

\section{METHODOLOGY}

\section{A. Alloy Composition}

The actual composition of $\mathrm{Al} 7075$ alloy obtained by spectrometric investigation is shown in table 1.

Table 1 composition of aluminium matrix

\begin{tabular}{|c|c|c|c|c|c|c|c|c|}
\hline $\begin{array}{c}\text { Eleme } \\
\text { nt }\end{array}$ & Si & Mg & Fe & Mn & Cr & Zn & Ti & Al \\
\hline wt\% & 0. & 2.2 & 0. & 0.2 & 1.9 & 6.1 & 0. & Balanc \\
& 4 & 5 & 4 & 6 & 6 & 2 & 2 & e \\
\hline
\end{tabular}

B. Steel powder reinforcement composition

The eutectoid steel powder (Water quench tool steel) of 20-30 micron size is used as reinforcement. The composition of reinforcement is shown in table 2 .

Table 2. Composition of steel powder

\begin{tabular}{|c|c|c|c|c|c|c|c|c|}
\hline $\begin{array}{c}\text { Eleme } \\
\text { nt }\end{array}$ & $\mathbf{C}$ & $\mathbf{M g}$ & $\mathbf{P}$ & $\mathbf{M n}$ & $\mathbf{C r}$ & $\mathbf{S i}$ & $\mathbf{S}$ & $\mathbf{F e}$ \\
\hline $\mathrm{wt} \%$ & 0.8 & 0.0 & 0. & 0.07 & 0.0 & 0.0 & 0.0 & Balan \\
& 1 & 5 & 2 & 1 & 2 & 5 & 2 & ce \\
\hline
\end{tabular}

The two types of composites, each containing 3 and $6 \mathrm{wt} \%$ of steel powder, are prepared by two step liquid stir casting and compared with base alloy. Castings are flattened to rectangular billets and polished to take out any surface irregularity and scale. Then billets are isothermally heated for 10 hours at $500^{\circ} \mathrm{C}$ in the salt bath furnace for diffusion annealing to eliminate any microscopic chemical inhomogeneity present in the matrix. Small pieces of $20 \mathrm{~mm}$ x $10 \mathrm{~mm} \times 10 \mathrm{~mm}$ are cut from the billets, a total of 20 to 30 numbers of specimens each are prepared from three casting groups.

\section{Microstructure}

For microstructure analysis the SEM microphotographs are taken after series of polishing stages and etching with Keller's reagent to analyse the distribution of reinforcements in aluminium alloy and its composites.

\section{Cold Rolling Treatment}

Before solutionising, specimens are undergone rolling by conventional two high rollers at room temperature. Thickness of specimen is reduced by providing a minimum deformation in each pass. By grinding and polishing with emery papers, burrs formed if any during rolling are removed. The specimens are undergone cold rolling, with10 and $20 \%$ deformations to stain the matrix.

\section{E. Solutionising}

In the salt bath, each set of deformed specimens is heated to $530^{\circ} \mathrm{C}$ and quenched in cold water until the temperature of the specimen decreases to room temperature for solutionising. Later, samples are isothermally aged at 100 and $180^{\circ} \mathrm{C}$. Hardness distribution vs aging time graphs are plotted for all samples at every one-hour aging intervals.

\section{F. Hardness Measurement}

All the specimens are subjected to Vickers hardness test and hardness numbers are noted. Peak hardness values (average of 5 consistent readings) are noted for age hardened as well as mechanically deformed samples.

\section{G. Aging}

Aging is executed by reheating the solutionised specimens at 100 and $180^{\circ} \mathrm{C}$ i.e., well below solvus temperature for numerous time durations to note down the aging pattern. Aging pattern, maximum hardness number and peak aging duration depend on aging temperature and composition of composites. Peak hardness value at different temperatures for different composites are noted from the hardness versus aging time duration curves.

\section{RESULTS AND DISCUSSION}

\section{A. Microstructure analysis:}

Before stepping to aging characteristics or testing, it is advisable to study the dispersion of reinforcements in the alloy matrix. The SEM images of the etched specimens, both alloy and composites in as-cast condition is shown in the figures 1(a), (b) and (c). The dark spots are the discrete eutectoid steel particles embedded in Al 7075 matrix. No agglomeration or scatter of particulates in the matrix is observed in all the composites. The Energy dispersive X-ray spectrum (EDX) of the composite signifying the elemental spreadout at matrix and reinforcement locations is also shown in figures 1(a), (b) and (c), representing the peak spectrum as reinforcement $\mathrm{Fe}$ (Steel), and matrix with $\mathrm{Al}, \mathrm{Zn}$ and $\mathrm{Mg}$.

\section{B. Hardness measurement}

Figures 2, 3 and 4 show the hardness distribution graphs with aging time in hours for age hardened base alloy specimens during aging at 100 and $180^{\circ} \mathrm{C}$ with and without prior deformations (10 and 20\%). Figures 5, 6 and 7 show hardness distribution graphs with aging time in hours for $\mathrm{Al}$ 7075-3 wt\% steel powder composite specimens during aging at 100 and $180^{\circ} \mathrm{C}$ with and without prior deformations (10 
and 20\%). Figures 8, 9 and 10 show similar graphs with aging time in hours for $\mathrm{Al} 7075-6 \mathrm{wt} \%$ steel powder composite specimens during aging at 100 and $180^{\circ} \mathrm{C}$ with and without prior deformations (10 and 20\%). The average of 5 consistent readings out of 8 readings are considered in the study. During aging, hardness value continuously increases, reaches maximum and later decreases with aging duration. This trend pattern is observed in all the composites used in this study. Several technical experts used the well-defined theory known as "Lattice coherency theory" to explain the concept responsible for this aging phenomenon [11-12]. The spontaneous evolution of several intermediate metastable coherent or partially coherent intermetallic phases precipitation leading to stable precipitates (intermetallics) is happening during aging [13]. Several transition zones are observed with considerable mechanical strain due to the continuous change in lattice structures during converging into stable phase. Maximum (Peak) hardness is observed for the given aging temperature for the given alloy or composite where lattice coherency is maintained between the matrix and the precipitated phases. Further growth of the intermediate metastable phases beyond the critical size coarsens the precipitates slowly to change over from semi-coherency to incoherency to record drop in the hardness values. This stage is known as overaging [14].

Lower the soaking temperature slower is the diffusion rate, longer is the time to achieve the coherency condition [15]. As the steel powder quantity in the composite increases or the degree of deformation increases the peak hardness value increases with decrease in aging time.

The typical hardness distribution pattern observed in all the cases is due to the combined effect of work hardening and lattice coherency. Approximately 10 to $30 \%$ increase in peak hardness and $30 \%$ reduction in the peak aging duration is observed with the combined effect of aging and prior deformation in the composites under consideration. Hence as the weight percentage of reinforcement or degree of deformation in the composite increases, peak hardness increases. Figures 11 and 12 show the comparison of peak hardness values of the composites during aging at 100 and $180^{\circ} \mathrm{C}$ respectively with and without prior deformations. Higher the deformation density followed by low temperature aging shows excellent peak hardness value whereas higher temperature aged shows lowest.

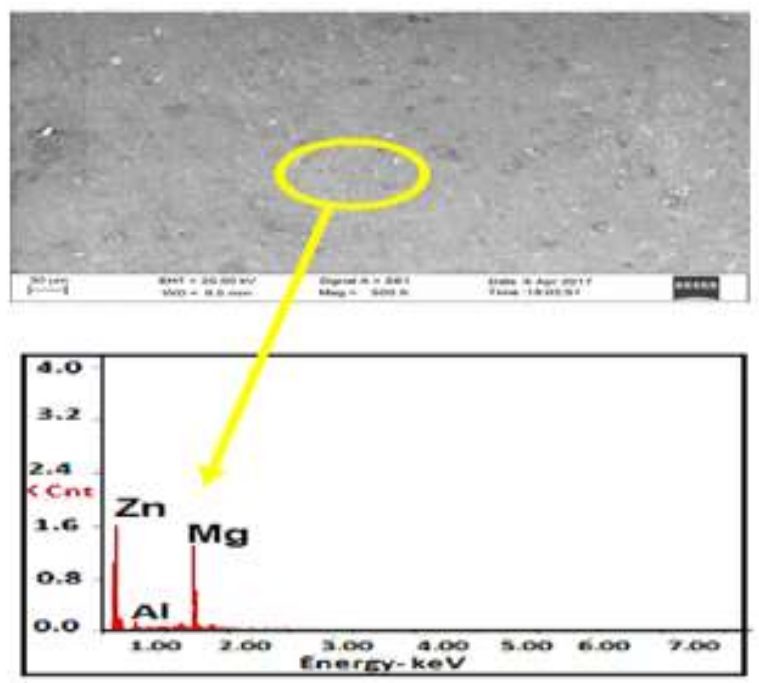

(a)
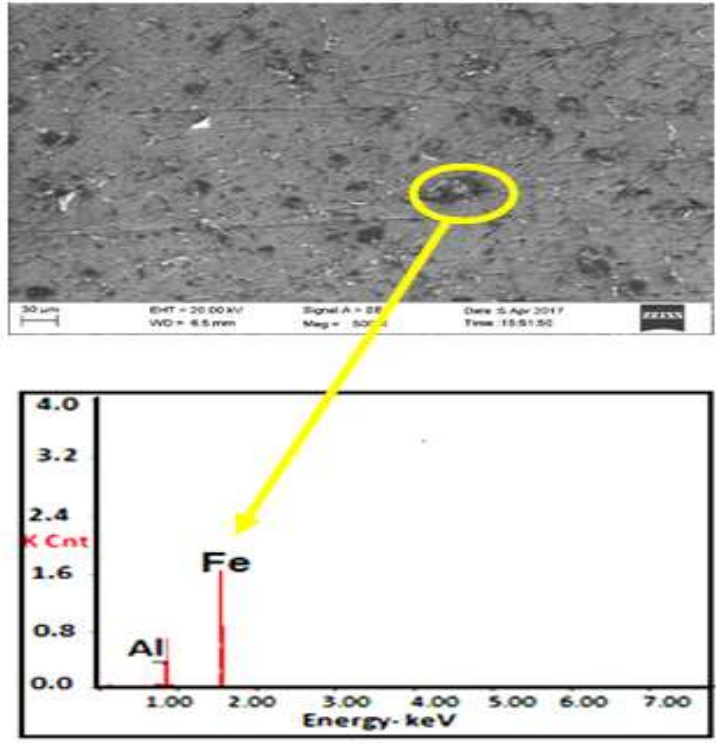

(b)
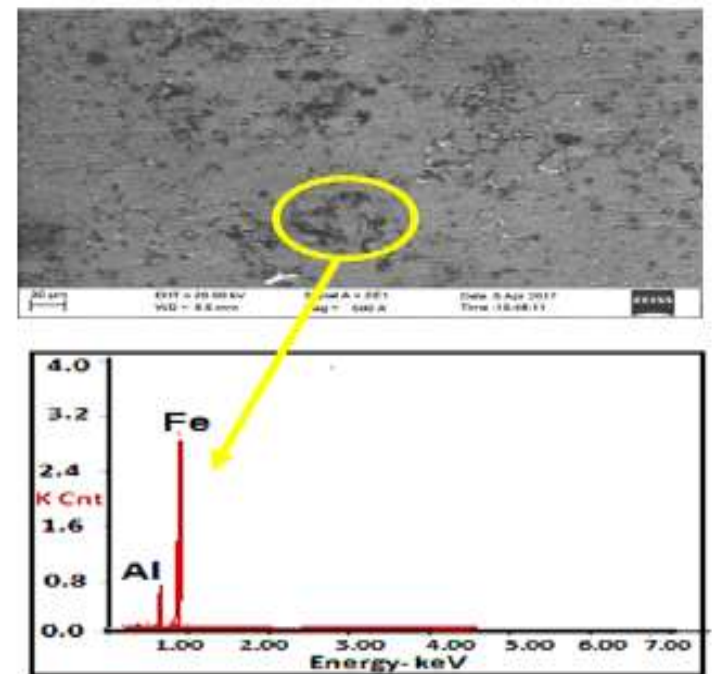

(c)

Figure 1: Microstructure and EDAX of as-cast (a) Al 7075 alloy (b) Al 7075-3 wt \% steel powder composite (c) Al 7075-6 wt \% steel powder composite

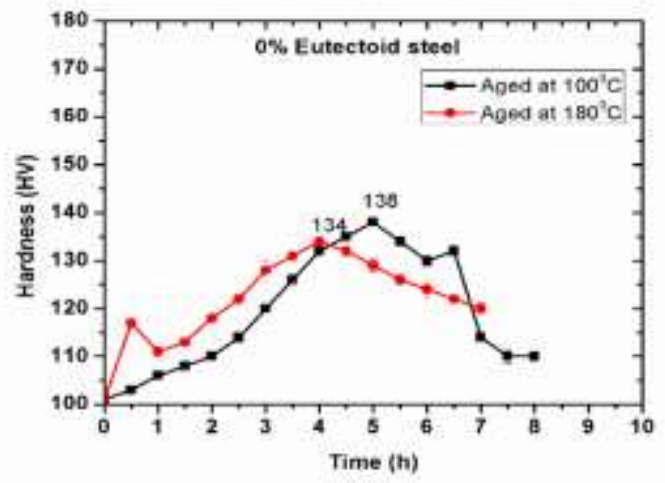

Figure 2: Aging curve for Al 7075 alloy without deformation at 100 and $180^{\circ} \mathrm{C}$ 
Prior Solutionising Deformation Consequence on the Aging Characteristics of Steel Powder Reinforced Al 7075 Composites

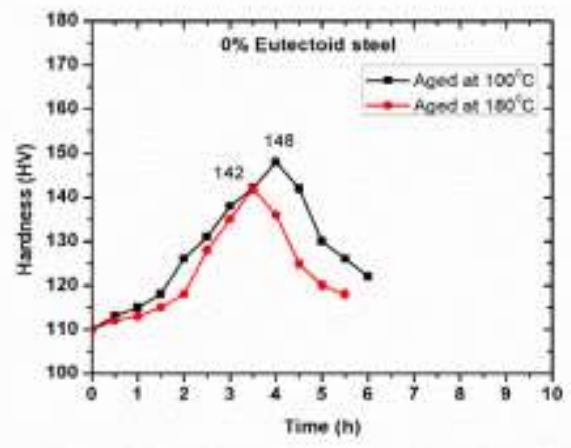

Figure 3: Aging curve for Al 7075 alloy with 10\% deformation at 100 and $180^{\circ} \mathrm{C}$

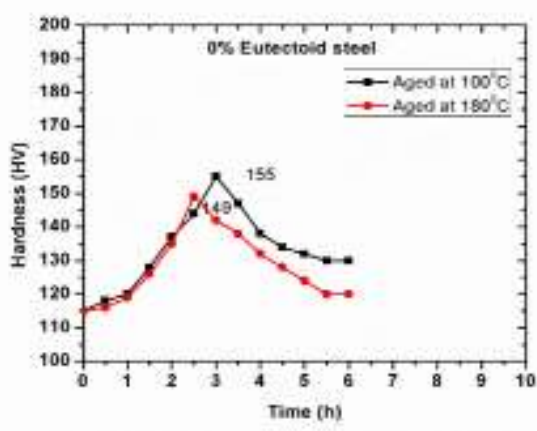

Figure 4: Aging curve for Al 7075 alloy with $20 \%$ deformation at 100 and $180^{\circ} \mathrm{C}$

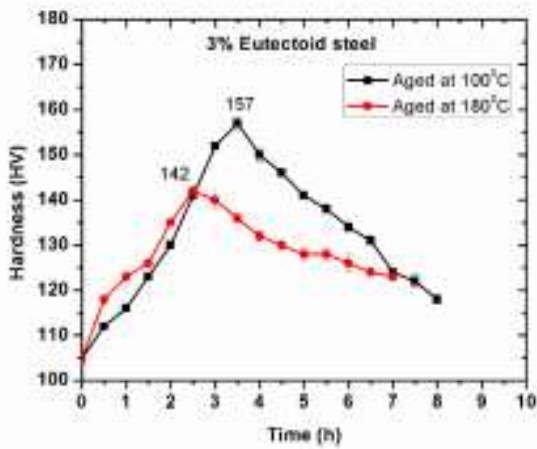

Figure 5: Aging curve for Al 7075-3\% steel powder composite without deformation at 100 and $180^{\circ} \mathrm{C}$

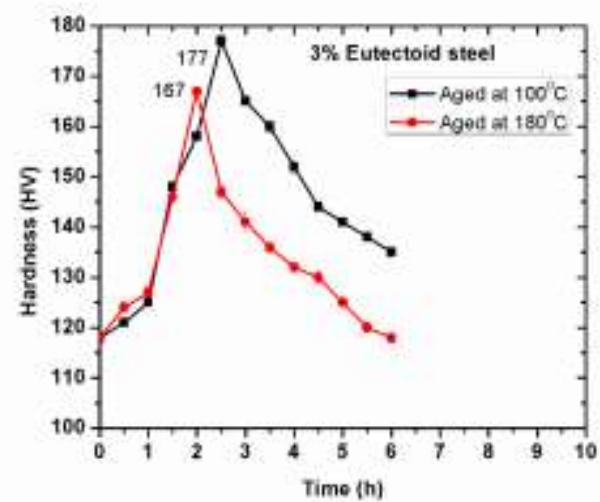

Figure 6: Aging curve for Al 7075-3\% steel powder composite with $10 \%$ deformation at 100 and $180^{\circ} \mathrm{C}$

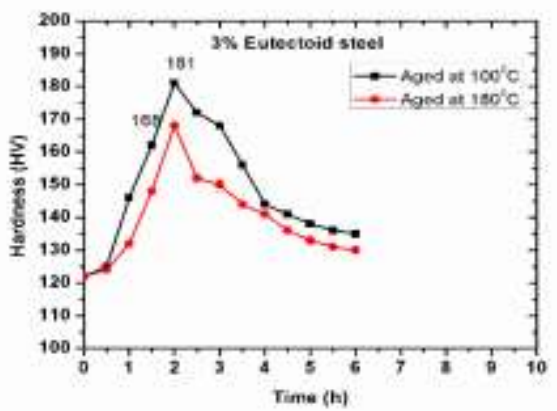

Figure 7: Aging curve for Al 7075-3\% steel powder composite with $20 \%$ deformation at 100 and $180^{\circ} \mathrm{C}$

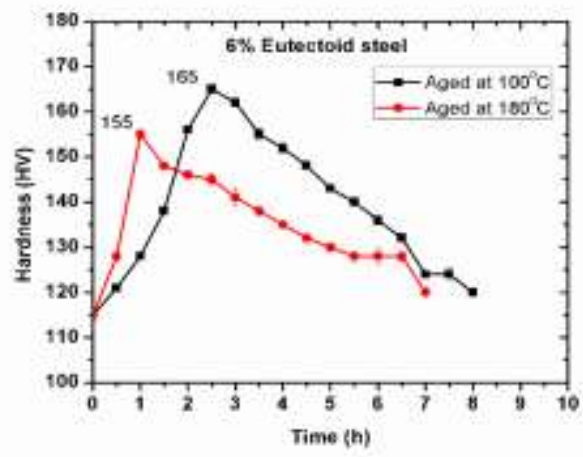

Figure 8: Aging curve for Al 7075-6\% steel powder composite without deformation at 100 and $180^{\circ} \mathrm{C}$

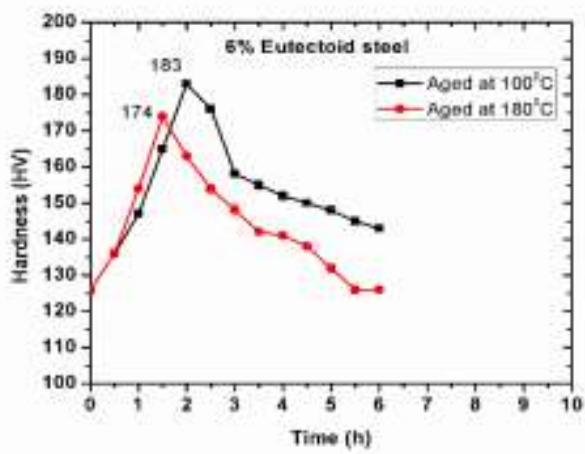

Figure 9: Aging curve for Al 7075-6\% steel powder composite with $10 \%$ deformation at 100 and $180^{\circ} \mathrm{C}$

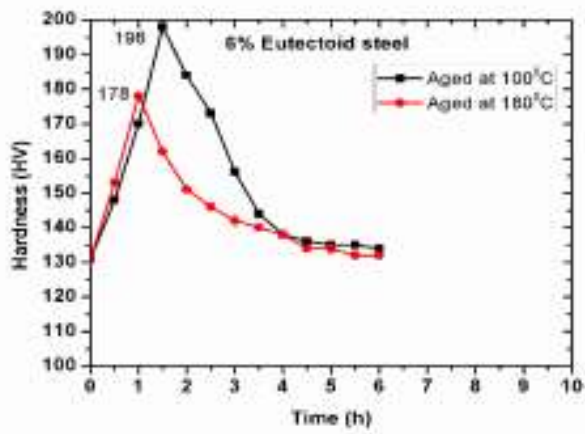

Figure 10: Aging curve for Al 7075-6\% steel powder composite with $20 \%$ deformation at 100 and $180^{\circ} \mathrm{C}$ 


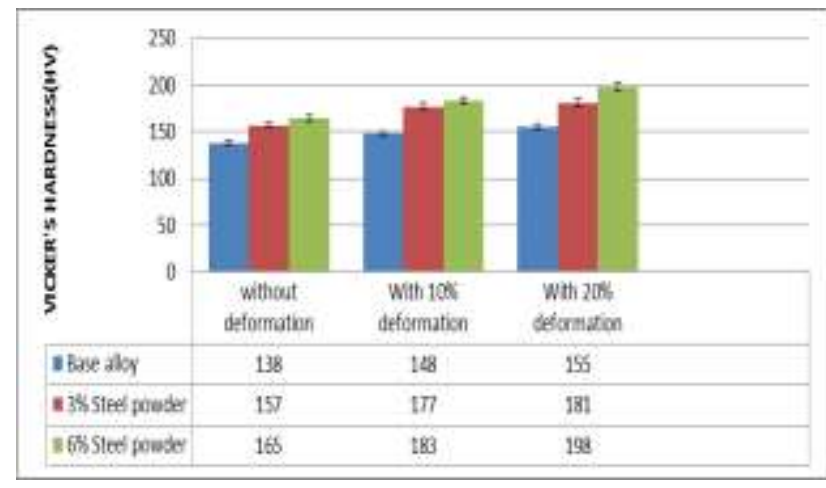

Figure 11: Comparison of peak hardness of the composites in as-cast and aging with and without prior deformation conditions (Aged at $\mathbf{1 0 0}^{\circ} \mathrm{C}$ )

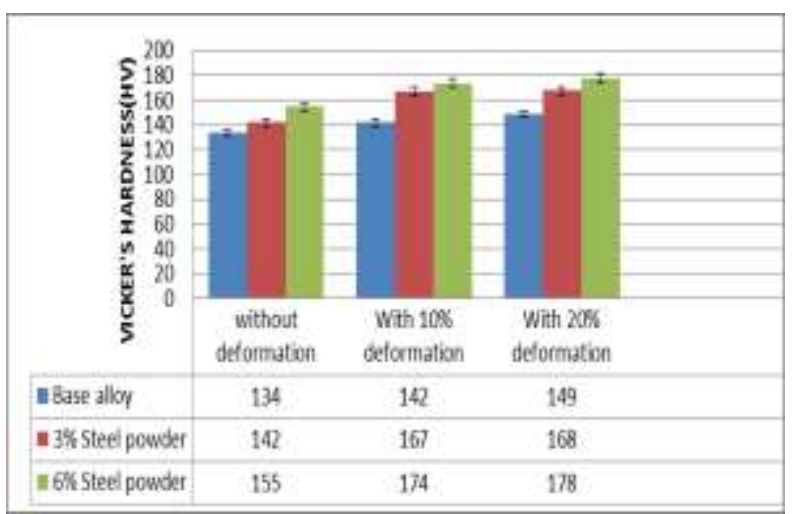

Figure 12: Comparison of peak hardness of the composites in as-cast and aging with and without prior deformation conditions (Aged at $180^{\circ} \mathrm{C}$ )

\section{CONCLUSION}

Al 7075 alloy and composites are efficaciously heat treated by age hardening with or without prior deformation. There is noteworthy enhancement in the hardness of the alloy and composites especially by prior deformation supported age hardening. In all the categories of the materials under consideration, lower aging temperature records maximum peak hardness values in age hardening with or without prior deformation. Cold rolling supported aging treatment shows higher peak hardness values compared to conventional age hardening. Higher the rolling deformation (20\%) higher is the hardness, shorter is the peak aging time. The SEM images of as-cast specimens shows good dispersal of steel powder in the matrix without scatter or agglomeration.

\section{REFERENCES}

1. Berg L. K, Gjonnes J, Hansen V, Li X. Z, Knutson-wedel, \& M, Waterloo G (2001) "GP-zones in Al-Zn-Mg alloys and their role in artificial aging" Acta Mater, 49, 3443-3465.

2. Vijendra Singh (2012) "Heat treatment of metals", 2nd Edition, Standard publishers and distributors, limited, New Delhi.

3. Chen S. P, Kuijpers NCW \& Vander Zwaag S (2003) "Effect of micro segregation and dislocations on the nucleation kinetics of precipitation in aluminium alloy AA3003”, Material Science Engineering, 341, 296-300.

4. Chen K. H, Liu H. W, Zhang Z, Li S \& Todd R. I (2003), "The improvement of constituent dissolution and mechanical properties of 7055 aluminum alloy by stepped heat treatments", Journal of Material Process Technology,
142, 190-196.

5. Dumont D, Deschamps A \& Brechet Y (2003) "On the relationship between microstructure, strength and toughness in AA7050aluminum alloy", Material Science Engineering, 356, 326-326.

6. Lee S. H, Saito Y, Sakai T \& Utsunomiya H (2002), "Microstructures and mechanical properties of 6061 aluminum alloy processed by accumulative roll-bonding", Material Science Engineering, 325, 228-235.

7. Robson J. D (2002), "Optimizing the homogenization of zirconium containing commercial aluminium alloys using a novel process model", Material Science Engineering, $338,219-229$.

8. Avner S H (2012) "Introduction to physical metallurgy", 3rd Edition, McGraw Hill, New Delhi.

9. Sjolender \& S. Seifeddine (2010), "Optimization of solution treatment of cast Al-Si-Cu alloys", Materials and Design, 31, 544-549.

10. Tangen Stian, Sjolstad Knut, Nes Erik, Furu Trond \& Marthinsen Knut (2002), "The effect of precipitation on the recrystallization behavior of a supersaturated, cold rolled AA3103 aluminium alloy”, Material Science Forum ,469, 396-402.

11. Veeresh Kumar, C. S. P. Rao, N. Selvaraj, \& M. S Bhagyashekar (2010), "Studies on Al6061-SiC and Al7075-Al2O3 Metal Matrix Composites", Journal of Minerals \& Materials Characterization \& Engineering, 9, 43-55.

12. Rajan T.V., Sharma C.P and Ashok Sharma (2012) "Heat treatment principles and techniques" 2nd Edition, PHI learning private limited, New Delhi.

13. Wang D, Nia D. R \& Ma Z. Y (2008), "Effect of pre-strain and two-step aging on microstructure and stress corrosion cracking of 7050 alloy", Material Science Engineering, 218-226.

14. Wang H.Q, Sun W.L \& Xing Y.Q (2013), "Microstructure analysis on 6061 aluminum alloy after casting and diffuses annealing process", Physics Procedia-Elsevier: 1, 68-75.

15. Yuvaraja \& N. Natarajan (2012), "Comparison on Al6061 and Al7075 alloy with SiC and B4C reinforcement hybrid metal matrix composites", Int Journal of Advanced Research in Tech., 2, 1-12.

\section{AUTHORS PROFILE}

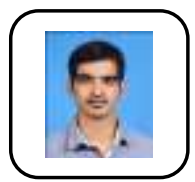

Rajesh is working as Research Scholar in the Department of Mechanical \& Manufacturing Engineering, MIT, MAHE, Manipal. He holds B.E. (Mechanica Engineering), M.Tech. (Manufacturing Engineering) degrees and Pursing Ph.D. (Materials). His area of interest includes materials engineering and heat treatment of metals. He has published 3 papers in journals and conferences.

Dr. Sathyashankara Sharma is working as Professor and Head in the Department of Mechanical \& Manufacturing Engineering, MIT, MAHE, Manipal. He holds B.E. (Industrial and production Engineering),

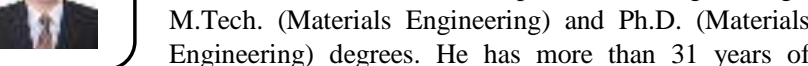

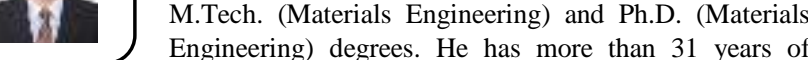
teaching experience. His area of interest includes materials engineering, heat treatment of metals and composites and deformation behavior of metals and composites. He has published more than 195 papers in journals and conferences.

Dr. Gowrishankar $\mathbf{M} \mathbf{C}$ is working as Associate Professor in the Department of Mechanical \& Manufacturing Engineering, MIT, MAHE, Manipal. He holds B.E. (Mechanical), Quality and Precision

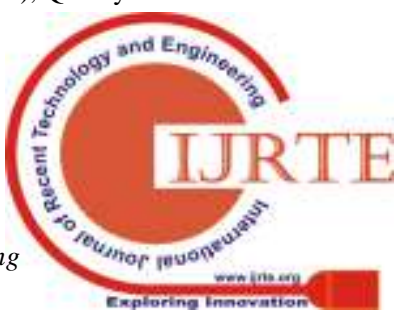


Engineering), Ph.D (Composite Materials) degrees. He has more than 14 years of teaching and industrial experience. His area of interest includes materials engineering, heat treatment of metals and composites and deformation behavior of metals and composites. He has published more than 50 papers in journals and

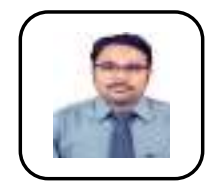

Mr. Manjunath Shettar is working as Assistan Professor (Sr. Scale) in the Department of Mechanical \& Manufacturing Engineering, MIT, MAHE, Manipal. He holds B.E. (Mechanical), M.Tech. (Production Engineering) degrees and Pursing Ph.D. (Composite Materials). He has more than 9 years of teaching and industrial experience. His area of interest includes composite materials and lean manufacturing. He has published more than 25 papers in journals and conferences.

Mr. Pavan Hiremath is working as Assistant Professor in the Department of Mechanical \& Manufacturing Engineering, MIT, MAHE, Manipal. He holds B.E. (Mechanical), M.Tech. (Manufacturing Engineering) degrees and Pursing Ph.D. (Materials). He has more than 4 years of teaching. His area of interest includes materials engineering and heat treatment of metals. He has published more than 20 papers in journals and conferences.

Anand Hegde is working as Assistant Professor in the Department of Mechanical Engineering, SMVIT, Udupi. He holds B.E. (I\&PE), M.Tech. (Materials Engineering) degrees and Pursing Ph.D. (Materials). He has more than 5 years of teaching. His area of interest includes materials engineering and heat treatment of metals. He has published more than 6 papers in journals and conferences. 